\title{
The evolution of emergency medicine: the pressing need for "made in Canada" subspecialty training
}

\author{
Jonathan Theoret, MDCM*; Geoff Sanz, MD; Amy Cheng, MD; Kevin Nemethy, MD*; \\ Shannon O’Donnell, MD*; Carolyn Kelly-Smith, MD ${ }^{\S}$
}

Emergency medicine (EM) is in a state of evolution. In 2010, the Royal College of Physicians and Surgeons of Canada adopted a new set of training requirements for EM. These guidelines have brought about numerous changes to residency training, including increased clinical time spent in the emergency department (ED) and a more structured approach to the postgraduate year (PGY)-4 subspecialty training year. Specifically, the guidelines state that residency must include "a minimum of 6 months devoted to achieving particular expertise in either a scholarly activity or a clinical area, pertinent to the practice of the specialty of Emergency Medicine. This activity must be clearly identifiable and structured, with specific activities, objectives and measurable goals."

Although training in specific areas is laudable, it does not create a recognized area of expertise as identified with a subspecialty. There are few formal scholarly or clinical subspecialty programs available in EM in Canada. Only the University of Ottawa ${ }^{2}$ and the University of Toronto ${ }^{3}$ provide detailed information on their locally available subspecialty training programs on their websites. The University of Western Ontario ${ }^{4}$ the University of Alberta, ${ }^{5}$ and the University of British Columbia ${ }^{6}$ mention subspecialty training but do not provide any specifics or state whether these fellowships are available. Although subspecialty training programs might be available at these and other institutions, this information is not readily available to prospective applicants. Furthermore, a search of the CFEM archive for the keyword "fellowship" yielded 50 scholarly articles but confirmed the existence of only clinical epidemiology ${ }^{7}$ and medical education ${ }^{8}$ fellowships at the University of Ottawa, an emergency medical services (EMS) fellowship at the University of Toronto, ${ }^{9}$ and a research fellowship at St. Paul's Hospital. ${ }^{10}$ Past EM graduates have completed degrees such as clinical epidemiology, public health, medical education, and master of business administration (MBA) and in medical informatics after completing their residency training. Such training is independent of the EM training program.

Pursuing clinical subspecialty training can be challenging in Canada. Only a limited number of positions are available in disciplines such as toxicology, critical care, sports medicine, clinical research, EMS, clinical ultrasonography, inner-city medicine, and palliative care. There are currently no formal training programs in Canada for simulation medicine, disaster medicine, or wilderness medicine. Existing Canadian fellowships are often administered by other specialties, and EM residents must compete for admission. Many are 2-year training programs, which in some cases do not permit starting the fellowship while still in residency. This imposes a PGY-6 year, at a minimum, and potentially a PGY-7 year. At the time of submission of this article, no comprehensive listings of Canadian subspecialty training programs were readily available to interested

From the Department of Emergency Medicine, *University of Alberta, Edmonton, AB; †Queen's University, Kingston, ON; $¥$ University of Toronto, Toronto, ON; and §University of British Columbia, Vancouver, BC.

Correspondence to: Dr. Jonathan Theoret, Department of Emergency Medicine, University of Alberta, 1G1.50 WC Mackenzie Centre, 8440-112 Street, Edmonton, AB T6G 2B7; jonathan.theoret@ualberta.ca.

Submitted April 24, 2010; Revised August 15, 2010; Accepted September 19, 2010.

This article has been peer reviewed. 
residents. These constitute significant barriers to the development of subspecialty training and, ultimately, to the advancement of EM.

The authors of this article are PGY-5 EM residents who recently completed subspecialty scholarly or clinical fellowships outside Canada. We present four accounts of our unique experiences: an MBA in Madrid with a public health focus; a wilderness medicine fellowship carried out in British Columbia, Colorado, and the United Kingdom; a master of public health $(\mathrm{MPH})$ in Paris and New York City; and a clinical ultrasonography fellowship in Denver, Colorado.

It is our goal to share our respective experiences with EM residents and to motivate them to take full advantage of the opportunity that the PGY-4 subspecialty training year offers. As the specialty continues to evolve, we anticipate that Canadian EM training programs will provide greater support and funding for residents to seek specialized training internationally. As more EM residents graduate from such fellowships and bring their unique expertise back to Canada, it is our vision that "made in Canada" subspecialty training programs will eventually develop.

\section{ULTRASONOGRAPHY FELLOWSHIP IN COLORADO}

\section{Geoff Sanz, MD; Jonathan Theoret, MDCM}

Given that clinical sonography is a relatively new area of expertise for EM in Canada, we decided to obtain our fellowship training in the United States. A short Internet search revealed a comprehensive listing of over 50 clinical EM ultrasound fellowships across the United States. ${ }^{11}$ This was the beginning of a melee of e-mails, an American Canadian Residency Matching Service-style interview tour, and, finally, the tumultuous task of obtaining a J-1 visa through Health Canada ${ }^{12}$ and the appropriate credentialing paperwork through its American counterpart, the Educational Commission for Foreign Medical Graduates. ${ }^{13}$ Ultimately, this landed two EM residents from opposite ends of the country in Denver, Colorado, in July 2009. There we began our hybrid year of clinical sonography and EM at the Denver Health Medical Center (DHMC) under the supervision of Dr. John Kendall, one of the foremost figures in clinical ultrasonography and coauthor of the leading textbook, Practical Guide to Emergency Ultrasound.${ }^{14}$ During our year in Denver, our respective programs considered us "away on elective" and our provincial funding was maintained. The DHMC EM residency program formally accepted us as their residents, which allowed us to be covered under their group medical malpractice and liability policy.

The DHMC clinical sonography fellowship is a 12-month intensive program. Our typical week consisted of two clinical EM shifts, 10 to 15 hours of EDbased scanning time, and a didactic teaching session with our fellowship director. Every Friday, all of the ultrasound fellows joined for video review, during which all of the studies performed would be reviewed. The fellowship was highly effective at expanding our clinical ultrasound knowledge but also covered important topics, such as strategies for effective teaching, quality assurance, physician credentialing, and establishment of formal ultrasound programs.

One administrative project worth highlighting was taken on by the DHMC clinical ultrasound fellows, Dr. Stephen Hoffenberg (a pioneer of clinical emergency ultrasonography), and a panel of experts on behalf of Hospital Corporation of America (HCA), the largest private operator of health care facilities in the United States. We developed a comprehensive toolkit and manual for the implementation of clinical ultrasound programs for the 163 hospitals that HCA operates across the United States. ${ }^{15}$ Given the stature of HCA in the US health care industry, as well as that of Dr. Hoffenberg in the clinical ultrasound community, it is anticipated that this document will serve as a standard guide for clinical ultrasound administration and accreditation.

Overall, our nontraditional fellowship year was a resounding success. It left us with a wealth of knowledge, a very unique perspective on the delivery and challenges of health care in North America, and an expertise in clinical ultrasonography that will likely shape the rest of our careers. Dr. Kendall and the DHMC community continue to be very supportive of Canadian residents interested in clinical sonography.

\section{AN MBA IN SPAIN}

\section{Amy Cheng, MD}

For my PGY-4 subspecialty year, I chose to do an MBA at IE Business School in Madrid, Spain. I chose an MBA because I wanted to learn how to apply principles from the private sector, such as efficiency 
and cost-effectiveness, to improve public delivery of health care both in Canada and abroad.

As front-line health care workers, emergency physicians are in a unique position to see the challenges of the health care system and to appreciate how health care policies can address these issues. Although emergency physicians are already taking on leadership roles, the lack of formal administrative training in some residency programs makes the associated administrative tasks daunting. In a recent article in The Wall Street Fournal, the chief of EM at San Francisco General Hospital discussed applying the skills he learned during the health administration course at Harvard University to improve the efficiency in his ED. ${ }^{16}$ Physicians are beginning to stress the importance of administrative courses in helping them acquire the skills necessary to improve the quality and efficiency of patient care.

I chose IE Business School for its 14-month intensive program, for its high rankings (consistently a top 10 MBA program internationally ${ }^{17}$ ), and because it is well known for training forwardthinking leaders. ${ }^{18} \mathrm{I}$ was confident that IE Business School would give me the skills to become a leader beyond the walls of the ED. I was able to complete the MBA by using the 12 months of my PGY-4 fellowship year in addition to 2 months of elective time. To maintain my clinical competence and to fulfill the University of Toronto residency program requirements for nonclinical fellowships, I flew back to Toronto to work in the ED during my two 1month vacation blocks in August and December. Furthermore, I was able to remain committed to my resident research projects during my MBA studies and had the opportunity to present my research findings at the Mediterranean Emergency Medicine Congress in September 2009.

The MBA has taught me how to lead a successful organization, as well as how to resolve problems during an organizational crisis. I have already started to apply these principles to the public health care sector. As a recipient of the IE Research Fellowship award, I worked with specialists at the PriceWaterhouseCoopers/IE Public Center on creating public-private partnerships to improve the efficiency of publicly delivered health care systems. Our group was invited to present our recommendations to the Madrid government and produced two major publications. ${ }^{19,20}$

\section{THE WILDERNESS ADVENTURE}

\section{Carolyn Kelly-Smith, MD}

I spent my PGY-4 year pursuing training in wilderness and mountain medicine (WMM). This specialized training has given me the skills and knowledge to provide medical care for prolonged periods of time in a harsh environment. Unique patient presentations, such as hypothermia, altitude sickness, and trauma secondary to avalanche, along with austere conditions make the practice of WMM significantly different from that of a typical ED. Furthermore, in the wilderness environment, personal and rescuer safety becomes a key factor in medical decisions.

As there is no official WMM fellowship training program available in Canada, I had to become creative when looking for educational opportunities. The Wilderness Medical Society (WMS), based in Salt Lake City, Utah, has a preestablished core curriculum of educational requirements that is combined with credits generated from practical experience to determine eligibility for fellowship designation in WMM. ${ }^{21}$

In addition, I enrolled in the diploma of mountain medicine (DMM) program based at the University of Leicester in the United Kingdom. The DMM program is the result of collaboration between the International Society of Mountain Medicine, the International Mountaineering and Climbing Federation, and the International Commission for Alpine Rescue. ${ }^{22}$ The DMM is based on four core elements: altitude and environmental medicine and physiology, travel and expedition medicine, mountain rescue, and trauma care and personal mountain skills.

Over the past year, I have worked toward fulfilling the practical experience requirements of the WMS fellowship in both Canada and the United States. Working with a Vancouver-based search-and-rescue organization, I have been transitioned to operating in a wilderness environment by Advanced Life Support paramedic mentors. Being part of the ski patrol at Whistler-Blackcomb in British Columbia has given me a novel experience with on-mountain trauma care and the difficulties of patient assessment and management in winter conditions. Finally, I worked in a medical clinic in Telluride, Colorado, where I was able to gain experience in the management of environmental illnesses such as acute mountain sickness and highaltitude pulmonary edema. 
In the United States, there are now fellowships offered in this subspecialty by several established EM programs. Unlike Canada, many European countries staff their fleets of mountain rescue helicopters with EM physicians. Although this may not be realistic in our country, Canadian rescue programs could potentially be improved with greater ED physician involvement. Canadian mountain rescue programs meet the International Commission for Alpine Rescue (ICAR) guidelines for on-site medical care less than $25 \%$ of the time versus nearly $100 \%$ compliance in many European programs. ${ }^{23}$

The out-of-country training I received this past year was excellent. Unfortunately, this education and experience were very expensive: adding travel expenses to the tuition costs for the diploma program left me paying more than $\$ 12,000$ over the past year, which my residency program could only partially support. Although it was great to learn from such experienced providers, I will have to adapt what I learned in Europe to practice in a Canadian environment with local resources. Being the only physician on a rescue team with our vast expanses of wilderness and limited resources is a different pattern of practice than is encountered in Europe.

With the unique training and practical experience I have obtained from my PGY-4 year, I hope to become a pioneer of the WMM subspecialty within Canada.

\section{AN INTERNATIONAL MPH}

\section{Shannon O'Donnell, MD; Kevin Nemethy, MD}

Our PGY-4 year was spent completing MPH degrees at École des hautes études en santé publique (EHESP; French School of Public Health) in Paris, France. Our decision to do an MPH was borne out of joint interests in inner-city medicine, access to care, population health, and health policy. We felt that a career bridging EM and public health has significant potential, as each field stands to benefit from the added perspective of the other. The ED is a key interface between the populace and the medical system, often for those most affected by injury and disease. Acute presentations seen in the ED are often those where community initiatives, from prevention programs to chronic disease care, are inadequate or do not yet exist. Relapses and readmissions often reflect a lack of hospital-based initiatives to ease the transition back into the community after discharge. Combined training in EM and public health will allow us to begin to explore the potential that exists for research and policy improvements that lie where these disciplines overlap. ${ }^{24}$

EHESP offers an international master's program taught entirely in English. ${ }^{25}$ It is a member school of the Association of Schools of Public Health in the European Region, an organization of more than 80 institutions, ${ }^{26}$ and has also recently established a collaborative relationship with Columbia University. ${ }^{27}$ The program is 2 years in duration but will allow direct entrance into the second year of the program based on previous education. ${ }^{28}$

The curriculum at EHESP is a hybrid between a course-based and a thesis-based MPH. The first 2 months are spent learning the core disciplines of public health (health policy and management, social and behavioural sciences, environmental health, biostatistics, epidemiology, and international health). The following 3 months are spent taking advanced elective courses in the above disciplines, which can be mixed toward a general MPH or focused toward a specialized degree. The final 5 months are spent in a vocational or academic practicum. Our practicums were spent working in the Department of Epidemiology at Columbia University in New York: one focused on mental health in ethnic and sexual minority populations and the other focused on cardiovascular risk associated with infectious disease. An opportunity also arose to design and conduct a mental health needs assessment in the aftermath of the earthquake in Haiti.

The greatest benefit of this particular MPH was that it took place in an international setting. We were able to share perspectives and experience and, more importantly, to develop strong friendships with individuals from Europe, Africa, the Middle East, Asia, South America, Mexico, and the United States. In addition to health professionals, our classmates included lawyers, political scientists, ethicists, health policy advisors, and lobbyists, to name a few.

Completing this MPH proved to be a valuable experience for both of us. We have obtained knowledge and developed skills that will aid us in both the academic and clinical realms of EM, and our perspectives on EM and on health care in general have been broadened. We eagerly returned to our PGY-5 year and the clinical medicine that we love, but we brought new knowledge, a broadened career outlook, and great memories with us.

Competing interests: None declared. 
Keywords: fellowship, master of business administration, master of public health, subspecialty training, ultrasonography, wilderness medicine

\section{REFERENCES}

1. Royal College of Physicians and Surgeons of Canada. Specialty training requirements in emergency medicine, 2010. Available at: http://rcpsc.medical.org/residency/ certification/training/emergmed_e.pdf (accessed July 2010).

2. Department of Emergency and Family Medicine, University of Ottawa. Available at: http://www.emottawa.ca/site/em_ fellowships.shtm (accessed July 2010).

3. Department of Medicine, Division of Emergency Medicine, University of Toronto. Available at: http://www.emergency medicine.utoronto.ca/Education/Fellowships/Application_ Procedures_and_Deadlines.htm (accessed July 2010).

4. Division of Emergency Medicine, University of Western Ontario. Available at: http://www.emlondon.ca/index.php? option $=$ com_content $\&$ task $=$ view $\&$ id $=114 \&$ Itemid $=219($ accessed July 2010).

5. Department of Emergency Medicine, University of Alberta. Available at: http://emergencymed.med.ualberta.ca/Home/ Education/Postgraduate/RCPSC/description.cfm (accessed July 2010).

6. Department of Emergency Medicine, University of British Columbia. Available at: http://emergency.med.ubc.ca/ education/residency_programs/royal_college_program.htm (accessed July 2010).

7. Dickinson G. Emergency medicine attains departmental status at the University of Ottawa. CFEM 2003;5:138.

8. Sibley A. CAEP 2005 Edmonton: resident awards. CFEM 2005;7:430

9. MacDonald RD, Schwartz B, Sawadsky BV, et al. A Canadian fellowship training program in emergency medical services. CFEM 2005;7:406-10.

10. Christenson J. Emergency medicine research fellowship - St. Paul's Hospital, UBC. CFEM 2000;2:130.

11. Emergency ultrasound fellowship. Available at: http://www .eusfellowships.com (accessed July 2010).

12. Health Canada. Statement of need for postgraduate medical training in the United States 2010. Available at: http://www .hc-sc.gc.ca/hcs-sss/hhr-rhs/postgrad-postdoc/index-eng.php (accessed July 2010).

13. Educational Commission for Foreign Medical Graduates. Available at: http://www.ecfing.org (accessed July 2010).

14. Cosby K, Kendall J. Practical guide to emergency ultrasound. Philadelphia: Lippincott Williams and Wilkins; 2006.
15. Hospital Corporation of America. HCA fact sheet. Available at: http://www.hcahealthcare.com/CustomPage.asp?guidCustom ContentID=89AAC3E7-7E84-4E62-9BF0-C33927FBFBC9 (accessed April 21, 2010).

16. Porter J. Doctors seek aid from business schools: universities, hospitals create programs to assist medical professionals in need of some management know-how. Wall Street Fournal, Online. Med Teach 2009;31:e311-5.

17. Global MBA ranking 2010. Financial Times 2010 Jan. Available at: http://rankings.ft.com/businessschoolrankings/ global-mba-rankings-2010 (accessed September 23, 2011).

18. Fast path to the fast track. The Wall Street fournal 2009 Sept 16. Available at: http://s.wsj.net/public/resources/documents/ st_mbamainchart_20090910.html (accessed September 23, 2011).

19. López M, Allard G, Badenes N, et al. Colaboración públicoprivada en la protección a la dependencia. Madrid: Editorial IE; 2010.

20. Allard G, Cheng A. Public private partnership in the Spanish health care sector. European Public Private Partnership Law Review 2009;4:82-7.

21. Wilderness Medical Society. Available at: http://www.wms .org/ (accessed July 2010).

22. International Commission for Alpine Rescue (ICAR). Available at: http://www.theuiaa.org/mountain_medicine .html (accessed July 2010).

23. Brugger H, Elsensohn F, Syme D, et al. A survey of emergency medical services in mountain areas of Europe and North America. High Alt Med Biol 2005;63:226-37, doi:10.1089/ham.2005.6.226.

24. Hauswald M, Gerson L, Kerr N. Public health and emergency medicine. Acad Emerg Med 2009;16:1040-3, doi:10.1111/j.1553-2712.2009.00541.x.

25. Master of Public Health. École des hautes études en santé publique. Available at: http://mph.ehesp.fr/ (accessed September 29, 2011).

26. ASPHER The Association of Schools of Public Health in the European Region. Available at: http://www.aspher.org/index. php? site=about_aspher (accessed September 29, 2011).

27. Partnership with French School of Public Health. Mailman School of Public Health, Columbia University. Available at: http://www.mailman.columbia.edu/academics/partnershipfrench-school-public-health (accessed September 29, 2011).

28. Eligibility - Master of Public Health (MPH). École des hautes Études en Santé Publique. Available at: http://mph .ehesp.fr/eligibility/ (accessed September 29, 2011). 